\title{
IS MEDICAL MARIJUANA LEGALISATION POSSIBLE IN POLAND?
}

\author{
Dorota Rogowska-Szadkowska, Julia Strumiło, Sławomir Chlabicz
}

Department of Family Medicine, Medical University of Bialystok, Bialystok, Poland

\section{SUMMARY}

Objectives: In some countries of the world it is legal to use plant-based marijuana for therapeutic purposes. When we had learned that 7,000 petitioners (including doctors) signed the petition to enable access to marijuana for patients in the Czech Republic, we decided to examine the knowledge about marijuana's medical properties among Polish medical students.

Methods: Anonymous questionnaire study was conducted on a group of 181 of students of the last (sixth) year of medical school.

Results: It was demonstrated that students are not provided with sufficient information about therapeutic administration of plant-based marijuana during medical studies. The majority of interviewees mentioned only one indication for medical marijuana use. All students did not interchange medical conditions for which marijuana is used in 30 USA states or Canada.

Discussion: Marijuana smoking for medical purposes differs from recreational smoking, and its effect does not depend on occurrence of symptoms from the central nervous system. Few studies, that were carried out along with numerous previously unreported cases of patients, demonstrated that plant-derived marijuana had therapeutic effect on many diseases where conventional medicine was of no help.

Conclusion: All doctors, including medical students, should receive more information about the therapeutic properties of marijuana.

Key words: medical marijuana, legalization, medical students, knowledge, attitudes

Address for correspondence: D. Rogowska-Szadkowska, Departament of Family Medicine and Community Nursing, Medical University of Białystok, Mieszka I 4b, 15-540 Białystok, Poland. E-mail: dszadkowska@umb.edu.pl.

https://doi.org/10.21101/cejph.a4578

\section{INTRODUCTION}

Marijuana was used for medical purposes for centuries, nevertheless, in the beginning of the 20th century more and more drugs containing marijuana had become prohibited, even though there was no proof of marijuana's harmful effect. Nonetheless, the knowledge about its therapeutic properties is spreading nowadays.

Until 2005, 70 cannabinoids and 419 other ingredients, including flavonoids, terpenoids, sugars, carbohydrates, steroids, simple alcohols, aldehydes, ketones, fatty acids, esters, aminoacids, proteins, lactones, and vitamins have been identified (1). In 2009, the number of known cannabinoids rose to 108 , belonging to 10 major types and 14 subtypes (2). Moreover, other cannabinoids are being searched for, but some of the methods of their isolation from marijuana, purification, synthesis, as well as their potential therapeutic applications are protected by patents (3). Plant-based marijuana contains other ingredients, such as terpenoids and flavonoids, which have therapeutic properties as well. The therapeutic effect of marijuana is not solely based on THC. It is a result of an interaction of all substances found in marijuana - cannabinoids, terpenoids and flavonoids (4).

Even before the United Nations Conventions de-legalized the use of cannabis, it was proven that cannabinoid acids, as precursors of cannabinoids, had antibiotic properties. They were used in Czechoslovakian veterinary medicine more than 50 years ago (5). Between the years 1950 and 1965, about 30 articles about marijuana were published in Czechoslovakia, 18 of them described its use as a locally acting antibiotic. A few cases of successful treatment of herpes and ulcerative gingivitis with marijuana ointments or sprays were reported, it was successfully used for ears, nose and throat (ENT) diseases, including otitis interna, chronic sinusitis, tonsillitis, and laryngitis. Analgesic properties of marijuana were also described, among others, in two cases of the second-degree burns. Those papers were not widely known, for the main reason that they were published solely in Czech (6), nevertheless, they are still brought up by the experts on the subject $(7,8)$.

At the end of the 20th century the comeback of marijuana's therapeutic administration started. The pioneer was the State of California (USA) in 1996, the next states followed afterwards. Currently, 29 states and the Columbia District legalized its use in treatment of some diseases. Moreover, the Compassionate Investigational New Drug Program, launched in 1978 (9), is still being implemented. For instance, two years ago four severely ill persons were receiving marijuana grown by the University of Mississippi from the program supervised by the National Institute on Drug Abuse (NIDA).

Canada became the first country to legalize medical marijuana, which was only possible due to court judgments in cases against severely ill people arrested by the police for the offence of growing cannabis for their personal use. The first judgment was given in the case of an epileptic patient, when the judge, after hearing expert opinions on the subject, acknowledged that regular moderate marijuana smoking does not cause physical and/or mental health damage for the majority of its users. It was acknowledged 
that growing marijuana is a logical step, allowing control of its quality, maximising the achieved benefits, and decreasing the risk of purchase of contaminated product. It drew attention to the fact that growing marijuana for personal consumption was an economic necessity (10).

Dutch pharmacies, as the first in the world, started selling marijuana to users with medical prescriptions in January 2013, and the Ministry of Health, Welfare and Sport obtained exclusive rights to grow and sell medically used marijuana (11). The Ministry of Health of Israel gave consent to use medical marijuana for the patients suffering from Crohn's disease, post-traumatic pain, in need of bone marrow transplant, and suffering from rheumatoid arthritis in 2006 (12).

In Germany, the use of medical marijuana was allowed in 2009 for severely ill patients suffering from chronic pain, multiple sclerosis, Tourette syndrome, cancer patients, and patients with HIV experiencing decreased appetite (13). An act to legalize the use of marijuana for medicinal purposes was passed by German parliamentarians. On January 19, votes were unanimous in favour of the new "cannabis as medicine" law, which will come into effect in March 2017. People with multiple sclerosis and other severe illnesses will be able to obtain the drug legally with a prescription. Doctors will also be able to prescribe marijuana or cannabis to patients for whom the drug could alleviate symptoms, such as chronic pain or nausea, or who may see a positive effect on their disease progression, according to a statement from the German Federal Ministry of Health (14).

In the Czech Republic, drugs derived from cannabis were legalized based on recommendation of the working group of the Government council for drug policy coordination that had been working on this case for months. The petition to legalize cannabis-derived pharmaceuticals signed by more than 7,000 Czech petitioners including doctors without any doubt had an impact on the commission (15). This information became a reason to investigate the knowledge and opinions of Polish medical students on the matter.

\section{MATERIAL AND METHODS}

In the first semester of the academic year 2013/2014, an anonymous questionnaire composed of 6 questions regarding medical marijuana was carried out among the students of the last (sixth) year of the Faculty of Medicine. A five-point Likert-type scale (definitely yes, rather yes, rather no, definitely no, undecided) was used. In the fifth, sixth and seventh open-ended questions the knowledge of the diseases in which marijuana could be used for therapeutic purposes was examined.

Statistical analysis was performed using Statistical package Statistica 7.0 P1.

\section{RESULTS}

The questionnaire was completed by 181 students, 113 females $(62.4 \%)$ and 68 males (37.6\%). The majority (81.9\%) of respondents were 24 and 25 years old ( 90 and 55 participants, respectively), 21 students were aged from 26 to 29 years (11.9\%), 4 respondents did not report their age.
The vast majority of students knew about marijuana's therapeutic effect (92.9\% of answers: definitely yes and rather yes). The majority of respondents also knew that marijuana helps patients suffering from severe wasting illnesses ( $87.3 \%$ of answers: definitely yes and rather yes). $98.8 \%$ of students supported the need of educating doctors about medical properties of marijuana as they had not been informed about them during their medical studies (79.5\% of students answered definitely no and rather no). $51.9 \%$ of students definitely supported and $25.4 \%$ rather supported legalization of marijuana for medical purposes in Poland. Detailed answers to the questions are provided in Table 1.

Students were also asked to list diseases, in which marijuana could be used for therapeutic purposes. They listed 20 medical conditions. The majority (126 people, 69.6\%) mentioned the usefulness of marijuana in cancer therapy, considerably fewer - in pain treatment (67 people, $37.0 \%)$, multiple sclerosis (30 people, 15.6\%), depression (21 people, 11.6\%), cachexia and/ or anorexia (18 people, 9.9\%), and glaucoma (13 people, $7.2 \%$ ). Only a few students mentioned marijuana use in palliative care, rheumatic diseases, epilepsy, Parkinson's disease, migraine, muscle spasticity, amyotrophic lateral sclerosis, Crohn's disease, and Huntington's disease (Table 2). The majority of interviewees mentioned only one indication for medical marijuana use. All students did not interchange medical conditions for which marijuana is used in 30 USA states or Canada.

Neither the place of residence of respondents (rural area, small or big city), nor the parents' level of education influenced the views of an interviewee. Students, who mentioned the desire to help people as a reason for choosing medical studies advocated for legalization of medical marijuana more often, but it was statistically insignificant.

None of the students knew that therapeutic use of a drug Sativex, which is an extract from cannabis strain containing large amount of tetrahydrocannabinol (THC - the only psychoactive cannabinoid), and large amount of cannabidiol (that has antipsychotic properties), used as a sublingual spray, is allowed in Poland.

One student wrote that marijuana, obviously an illegal drug, should not be advertised during classes at medical school. During the in-class discussion following the questionnaire filling, students admitted that they were taught that marijuana was an illegal drug, just like heroin and cocaine, when they took psychiatry class.

\section{DISCUSSION}

Unlike in the USA and Western Europe, where the society had a chance to get used to wide use of marijuana in the sixties and seventies of the 20th century, in Poland, which was rather isolated from the world, psychotropic medicines were used or glues and solvents were sniffed at that time (16). Marijuana became available in Poland after 1989, during the political transformation, yet with the reputation of a dangerous, addictive drug.

De-legalization of marijuana a few decades ago was a reason for not investigating or studying its therapeutic effects. Yet the few studies, that were carried out along with numerous previously unreported cases of patients, demonstrated that plant-derived marijuana had therapeutic effect on many diseases where conventional medicine was of no help. It is also worth mentioning 
Table 1. Students' answers to questions used in the questionnaire on medical use of marijuana $(N=181)$

\begin{tabular}{|c|c|c|c|c|c|}
\hline & $\begin{array}{l}\text { Definitely } \\
\text { yes }\end{array}$ & $\begin{array}{l}\text { Rather } \\
\text { yes }\end{array}$ & $\begin{array}{c}\text { Rather } \\
\text { no }\end{array}$ & $\begin{array}{c}\text { Definitely } \\
\text { no }\end{array}$ & Undecided \\
\hline & $\mathrm{n}(\%)$ & $n(\%)$ & $\mathrm{n}(\%)$ & $\mathrm{n}(\%)$ & $\mathrm{n}(\%)$ \\
\hline \multirow{2}{*}{ Does marijuana have therapeutic properties? } & $127(70.2)$ & $41(22.7)$ & $6(3.3)$ & $1(0.5)$ & \multirow{2}{*}{$6(3.3)$} \\
\hline & \multicolumn{2}{|c|}{$168(92.9)$} & \multicolumn{2}{|c|}{$7(3.8)$} & \\
\hline \multirow{2}{*}{$\begin{array}{l}\text { Does marijuana help patients suffering from severe } \\
\text { wasting diseases? }\end{array}$} & $115(63.5)$ & $43(23.8)$ & $8(4.4)$ & $3(1.7)$ & \multirow{2}{*}{$12(6.6)$} \\
\hline & \multicolumn{2}{|c|}{$158(87.3)$} & \multicolumn{2}{|c|}{$11(6.1)$} & \\
\hline \multirow{2}{*}{$\begin{array}{l}\text { Did you receive information about therapeutic } \\
\text { properties of marijuana during your medical studies? }\end{array}$} & $12(6.6)$ & $20(11.0)$ & $60(33.1)$ & $84(46.5)$ & \multirow{2}{*}{$5(2.8)$} \\
\hline & \multicolumn{2}{|c|}{$32(17.6)$} & \multicolumn{2}{|c|}{$144(79.6)$} & \\
\hline \multirow{2}{*}{$\begin{array}{l}\text { Do you think that information about marijuana is } \\
\text { necessary for doctors? }\end{array}$} & $144(79.6)$ & $36(19.3)$ & $0(0)$ & $0(0)$ & \multirow{2}{*}{$2(1.1)$} \\
\hline & \multicolumn{2}{|c|}{$180(98.9)$} & \multicolumn{2}{|c|}{$0(0)$} & \\
\hline \multirow{2}{*}{$\begin{array}{l}\text { In some countries of the world medical use of } \\
\text { marijuana was legalized. Do you think that the law } \\
\text { in Poland should be changed as well? }\end{array}$} & $94(51.9)$ & $46(25.4)$ & $14(7.7)$ & $9(5.0)$ & \multirow{2}{*}{$18(10.0)$} \\
\hline & \multicolumn{2}{|c|}{$140(77.3)$} & \multicolumn{2}{|c|}{$23(12.7)$} & \\
\hline
\end{tabular}

Table 2. Diseases for which marijuana could be applied medically

\begin{tabular}{|c|c|c|}
\hline Diseases listed most often ( $\mathrm{n}$ ) & Diseases listed by less than 10 people (n) & Diseases listed by $1-2$ people ( $n$ ) \\
\hline $\begin{array}{l}\text { - cancer (126) } \\
\text { - pain therapy (67) } \\
\text { - multiple sclerosis (30) } \\
\text { - depression (21) } \\
\text { - cachexia, anorexia (18) } \\
\text { - glaucoma (13) }\end{array}$ & $\begin{array}{l}\text { - palliative care (9) } \\
\text { - rheumatic diseases (9) } \\
\text { - epilepsy (6) } \\
\text { - Parkinson's disease (6) } \\
\text { - mental illnesses (6) } \\
\text { - migraine (6) } \\
\text { - muscle spasticity (6) } \\
\text { - nausea and vomiting (6) } \\
\text { - addictions (3) } \\
\text { - Crohn's disease (3) }\end{array}$ & $\begin{array}{l}\text { - amyotrophic lateral sclerosis (ALS) (2) } \\
\text { - Huntington's disease (2) } \\
\text { - allergy (1) } \\
\text { - leukaemia (1) }\end{array}$ \\
\hline
\end{tabular}

$\mathrm{n}$ - number of students that listed the disease

that marijuana smoking for medical purposes differs from recreational smoking, and its effect does not depend on occurrence of symptoms from the central nervous system (17).

The adverse effects of marijuana are not dangerous for life and health, the lethal overdose is not possible, unlike the overdose of opioids - prescription drugs, overused in many developed countries. Many severely ill people prefer adverse effects of marijuana which they describe as easier to bear compared to the adverse effects of drugs manufactured by the pharmaceutical industry (18).

It is possible to use therapeutic properties of marijuana with the use of vaporisers - devices in which the dried plant is heated to the temperature lower than the temperature of burning, that enables to inhale the released cannabinoids, terpenoids, and flavonoids, which have therapeutic properties as well. This way, inhaling potentially carcinogenic products of burning is avoided (19).

Future Polish doctors realise the medical properties of marijuana, but the chance that they will demand legal access to it is quite small. They learn nothing or very little about its advantages, in the meantime the media bring stories about dangers of smoking marijuana or illegal plantations almost on a daily basis. The diseases mentioned by students, in which marijuana could be applied, are indeed found on the list of approved applications in the USA, Canada and the Netherlands. None of the students mentioned HIV/AIDS, the disease that is mentioned first among the diseases, in which marijuana could be applicable in all 29 states and the Columbia District of the USA.

It would be in the interest of many severely ill people if marijuana became a medical issue, not political one, given that its therapeutic properties are not based on one or two cannabinoids extracted from cannabis, but on the interaction of all of them, including terpenoids and phenols, that have therapeutic properties as well. Besides, plant-derived marihuana is significantly cheaper than the extracts produced by pharmaceutical company. What is more, good experiences with plant medical marijuana have prompted several US states to legalize it for all adult residents. The access to medical marijuana could be in the interest of public health, as its use decreases the requirement for other, often considerably less safe, psychoactive substances (20).

Thirty years ago, in 1988, the US Drug Enforcement Administration (DEA) Chief Administrative Law Judge Francis Young determined: "Marijuana, in its natural form, is one of the safest therapeutically active substances known to man. By any measure of rational analysis marijuana can be safely used within a supervised routine of medical care. (...) At present, it is estimated that marijuana's LD-50 (median lethal dose) is around $1: 20,000$ or $1: 40,000 . "(21)$.

All doctors, including medical students, should receive more information about the therapeutic properties of marijuana. 


\section{Authors' Contributions}

DRS - constructing and distributing questionnaire to participants, text writing, literature search, final text editing, JS - analysing data, text writing.

\section{Conflict of Interests}

None declared

\section{Adherence to Ethical Standards}

The Ethics approval was obtained from Ethical Committee of the Medical University of Białystok.

\section{Acknowledgements}

This study was supported by internal sources from the Medical University of Bialystok (N/ST/ZB/17/002/3331).

\section{REFERENCES}

1. ElSohly MA, Slade D. Chemical constituents of marihuana: the complex mixture of natural cannabinoids. Life Sci. 2005 Dec 22;78(5):539-48.

2. Hanuš LO. Pharmacological and therapeutic secrets of plant and brain (endo)cannabinoids. Med Res Rev. 2009 Mar;29(2):213-71.

3. Galal AM, Slade D, Gul W, El-Alfy AT, Ferreira D, ElSohly MA. Naturally occurring and related synthetic cannabinoids and their potential therapeutic applications. Recent Pat CNS Drug Discov. 2009 Jun;4(2):112-36.

4. Russo EB, McPartland JM. Cannabis is more than simply delta(9)-tetrahydrocannabinol. Psychopharmacology (Berl). 2003 Feb;165(4):431-2.

5. Mechoulam R. Plant cannabinoids: a neglected pharmacological treasure trove. Br J Pharmacol. 2005 Dec;146(7):913-5.

6. KrejčiZ.Antibacterial action of Cannabis sativa. Lek Listy 1952;7(20):5003. (In Czech)

7. Cohen S. Therapeutic aspects. In: Petersen RC, editor. Marihuana research findings: 1976. Research Monograph series 14. July 1997. Rockville (MD): National Institute on Drug Abuse; 1976. p. 194-225.

8. Iversen LL. The science of marijuana. New York: Oxford University Press; 2000.

9. Russo E, Matre ML, Byrne A, Velin R, Bach PJ, Sanchez-Ramos J, et al. Chronic cannabis use in the Compassionate Investigational New Drug
Program: an examination of benefits and adverse effects of legal clinical cannabis. J Cannabis Ther. 2002;2(1):3-57.

10. Gray C. Legalize use of marijuana for medical purposes, MDs and patient plead. CMAJ. 1998 Feb 10;158(3):373-5.

11. Bogdanoski T. Accommodating the medical use of marijuana: surveying the differing legal approaches in Australia, the United States and Canada. J Law Med 2010 Feb;17(4):508-31.

12. Crowther SM, Reynolds LA, Tansey EM, editors. The medicalization of cannabis. Witness seminar transcript. London: Trustee of the Wellcome Trust; 2010.

13. Stafford N. Seven patients in Germany are granted use of marijuana for medical purposes. BMJ. 2009 Feb 20;338:b738.

14. CNN.com [Internet]. Cable News Network; 2017 Mar 6 [cited 2018 Jan 18]. Senthilingam M. Germany joins the global experiment on marijuana legalization. Available from: http:/edition.cnn.com/2016/12/29/health/ global-marijuana-cannabis-laws/index.html.

15. Palata N. In January, the Czechs get a marijuana prescription. Gazeta Wyborcza [Internet]. 2011 Oct 4 [cited 2018 Jan 18]; (232):8. Available from: http://www.archiwum.wyborcza.pl/ Archiwum/1,0,7484396,20111004RP-DGW,W_styczniu_Czesi_dostana marihuane na recepte,zwykly.html. (In Polish.)

16. Rychert M, Palczak K, Zobel F, Hughes D. European Monitoring Centre for Drugs and Drug Addiction. Drug policy profile: Poland, EMCDDA Papers. Luxembourg: Publications Office of the European Union; 2014.

17. Rogowska-Szadkowska D. Medical marijuana. History of hypocrisy. Warszawa: Wydawnictwo Krytyki Politycznej; 2016. (In Polish.)

18. Gable RS. Comparison of acute lethal toxicity of commonly abused psychoactive substances. Addiction. 2004 Jun;99(6):685-96.

19. Shiplo S, Asbridge M, Laetherdale ST, Hammond D. Medical cannabis use in Canada: vapourization and modes of delivery. Harm Reduct J. 2016 Oct 29;13(1):30.

20. Bachhuber MA, Saloner B, Cunningham CO, Barry CI. Medical cannabis laws and opiod analgesic overdose mortality in the United States, 1999-2010. JAMA Intern Med. 2014 Oct;174(10):1668-73. Erratum in: JAMA Intern Med. 2014 Nov;174(11):1875.

21. Annas GJ. Reefer madness - the federal response to California's medicalmarijuana law. N Engl J Med. 1997 Aug 7;337(6):435-9.

Received October 1, 2015 Accepted in revised form January 18, 2018 